\title{
Televisão: ficção seriada e intertextualidade
}

Anna Maria Balogh

Professora livre-docente aposentada do Departamento de Cinema, Rádio e TV da ECA/USP $e$ atualmente professora titular do Programa de Pós-graduação em Comunicação da UNIP. Autora, entre outros livros, de O Discurso Ficcional na TV (Edusp, 2002) e ConjunçõesDisjunções-Transmutações. Da Literatura ao Cinema e à TV (Annablume, 1995, 2. ed. rev. e ampl.), além de artigos em revistas e jornais especializados no Brasil e no exterior.

E-mail: balogh@terra.com.br

A cultura pode ser definida no âmbito das ciências da linguagem como um conjunto de textos, bem como as relações que se estabelecem entre eles. Para os formalistas russos, os textos podem ser de uma mesma série cultural, pressupondo-se que guardem entre si um conjunto de traços, de características similares, os quais permitam considerá-los sob uma rubrica comum. As características de cada série vão sendo definidas e aprimoradas através da metalinguagem, que delas se ocupa. Assim, a série literária vem sendo há muito definida pela teoria literária e pela semiótica da literatura, entre outras.

Cada cultura se forma a partir de um conjunto ponderável de séries, tais como a literária, a pictórica, a musical, a escultórica etc. Dentre as várias séries formadoras da cultura brasileira, a que nos concerne mais de perto neste trabalho é a série ficcional de TV.

O conceito de texto, sempre no âmbito das ciências da linguagem, se baseia na relação dialógica deste com o discurso. O discurso entendido como linguagem posta em ação pelo escritor ou pelo realizador de produtos audiovisuais; seria ainda, no entender de E. Lopes ${ }^{1}$, o espaço de semioses virtuais, o resultado do fazer de um destinador da mensagem, e o texto constituiria o espaço da semiose realizada, na qual o destinatário desvenda o dizer do destinador através da leitura no literário e da apreciação ou fruição, no fílmico e no televisual. Dentro de tal contexto, a obra só seria então completa, acabada, quando lida, decodificada e interpretada pelo destinatário.

A cultura é, portanto, o conjunto dos textos que abarcam as diferentes séries que a constituem, bem como o intrincado tecido de relações que, no entender de Octavio $\mathrm{Paz}^{2}$, tal textualidade pressupõe.

\section{CONTEMPORANEIDADE E NOVOS TECIDOS DE RELAÇÕES}

Se é verdade que a cultura sempre se caracterizou pelo vasto tecido de relações entre textos, não é menos verdadeiro que tais relações passaram por transformações ponderáveis no mundo contemporâneo. Antes de abordar o

1. LOPES, Edward. Discurso, texto e significação. São Paulo: Cultrix 1978. p. 6.

2. PAZ, Octavio. Corriente alterna (Corrente alternada). México: Siglo $X X I, 1969$. p. 1. 
3. Apud JENNY, Laurent. Stratégie de la forme (Estratégia da forma). Poétique, n. 27, p. 257 281, 1976.

4. Ibid.

5. GLOWINSKI, Michal. Acerca de la intertextualidad (Sobre a intertextualidade). Criterios, La Habana, n. 32, p. 188, 1994.

6. GENETTE, Gérard Palimpsestes: la littérature au deuxième degré (Palimpsesto: a literatura em segundo plano). Paris: Du Seuil, 1982.

7. GLOWINSKI, op. cit., p. 190-1.

8. Ibid. fenômeno sob novos ângulos, convém, no entanto, retomar a definição clássica do termo "intertextualidade", cunhado por Julia Kristeva:

A intertextualidade designa não uma adição confusa e misteriosa de influências, mas o trabalho de assimilação de diversos textos realizado por um texto centralizador que mantém a liderança do sentido ${ }^{3}$.

Tal definição foi posteriormente revista por críticos como Michel Arivé e Laurent Jenny ${ }^{4}$, entre outros. Mais recentemente, em seu artigo sobre o tema, Michal Glowinski lembra que, na época de sua concepção, os conhecimentos da estrutura do texto ainda não eram tão avançados quanto podem ser considerados atualmente; nesse sentido, propõe algumas revisões que teriam como objetivo precisar melhor o termo, no seu entender utilizado em um sentido demasiado amplo pela pioneira crítica. Para Glowinski, diversamente do passado em que o termo era mais associado à pesquisa de fontes, hoje se considera que sob a rubrica de intertextualidade "entran exclusivamente aquellas relaciones intencionales y de una u otra manera visibles, se podría decir destinadas al lector ${ }^{5}$ ".

$\mathrm{Na}$ realidade, a maioria dos ensaios pioneiros sobre intertextualidade tem como objeto a série literária, e só em épocas mais recentes tais conceitos vão sendo revistos à luz das características peculiares de meios de comunicação de massa, tais como a TV.

Em seu artigo, Glowinski faz uma revisão crítica da obra mais clássica sobre o tema: Palimpsestes, de Gérard Genette ${ }^{6}$. A classificação de Genette, assim como as precisões e acréscimos do crítico polonês, têm como objeto privilegiado a série literária. As principais categorias propostas pelo teórico francês seriam as seguintes: intertextualité, paratextualité, hipertextualité, metatextualité, transtextualité e architextualité. Ao fazer suas observações críticas no tocante a essa classificação, Glowinski considera haver uma superposição das funções hipertextuais e intertextuais e pondera que se pode manter o termo mais consagrado, intertextualidade, e descartar o outro ${ }^{7}$. Propõe, ainda, o descarte do termo paratextualidade para o literário, assim definido "en el marco de ésta (paratextualidad) entra toda clase de comentarios a la obra encerrados en la obra misma, a saber: prólogos, epílogos, títulos, epígrafes etc.”.

\section{PARATEXTUALIDADE E TV}

No tocante à paratextualidade, notam-se diferenças ponderáveis entre seus limites e funções na literatura e na TV. Nesse sentido, pode se revelar muito oportuna a retomada da definição do termo por parte do crítico de televisão Lorenzo Vilches, que utiliza indiferentemente os termos parasserialidade e paratextualidade para designar assim o fenômeno:

La paratextualidad se refiere a todas aquellas notas al margen de la serie: títulos, subtítulos, presentación y portada, apertura, leitmotif musical, la publicidad en torno a su emisión, la información entre cambios y ajustes de horario, los comen- 
tarios de la prensa, etc. son todos elementos que, sin pertenecer a la serie actúan para-ella, en forma enmascarada haciendo el chivato y colocándose cómoda e impunemente fuera de la norma del género ${ }^{9}$.

A paratextualidade na TV é muito mais abarcadora, muito mais necessária na mediação entre a programação da emissora e o público, principalmente pelo fato de que o veículo se insere muito mais enfaticamente no mundo das novas tecnologias caracterizadas pela velocidade e pela voracidade, traços que a afastam do universo do livro tradicional. A televisão é, como já tivemos ocasião de dizer alhures, um grande Pantagruel eletrônico devorador de programas diários, caracterizada pela estética da interrupção ${ }^{10}$ e da repetição ${ }^{11}$, e dirigida a um público massivo de milhões e milhões de espectadores. Como bem lembraram Michèle e Armand Mattelart ${ }^{12}$, no Brasil a TV adquire uma representatividade social desmesurada, gerando interesses e expectativas as mais variadas por parte do público. Nesse sentido, nota-se uma multiplicação crescente de suplementos de jornais e de revistas girando em torno do assunto, referindo-se às séries e aos mais variados aspectos de sua realização, complementando e orientando o ver dos espectadores em relação à série, e que multiplicam esses elementos paratextuais mencionados.

Precisamente por causa das características específicas da televisão, que exigem a criação de competências céleres para possibilitar o posicionamento correto do espectador dentro de uma grade de programação, a paratextualidade é constituída de um grande número de gêneros e formatos diversos que exigem prontidão no reconhecimento e no posicionamento do espectador perante os variados programas. Nesse sentido, vinhetas, músicas e as próprias chamadas servem como verdadeiras bulas instrutivas para a decodificação. Em suma, ao contrário do que ocorre na série literária, em que a paratextualidade é dispensável, na opinião do crítico polonês, no caso da televisão torna-se um instrumento imprescindível na orientação do fruir do espectador, opinião já manifesta pela articulista em relação às séries brasileiras em $O$ Discurso Ficcional na $T V^{13}$.

Além dos elementos já citados como pertencentes à paratextualidade, a televisão mantém outros recursos estáveis ou estabilizadores para fazer frente à intensa celeridade e voracidade da programação e do veículo: os gêneros e formatos costumam se reiterar com pequenas variáveis dentro da grade horária, tendo em mente um espectador cativo. Trata-se de características essenciais no processo comunicacional da TV. Tais raciocínios nos conduzem naturalmente a outra das categorias propostas por Genette e revistas por Glowinski: a da arquitextualidade.

\section{ARQUITEXTUALIDADE E TELEVISÃO}

A arquitextualidade, tal como revista por Glowinski a partir de Genette, "consiste en que el texto remite siempre a las reglas generales conforme las cuáles
9. VILCHES, Lorenzo. Play it again, Sam (Toque de novo, Sam). Anàlisi, Barcelona, n. 9, p. 68, 1984.

10. VIRILIO, Paul; LOTRINGER, Silvere. Guerra pura: a militarização do cotidiano. São Paulo: Brasiliense, 1984. p. 42.

11. CALABRESE, Omar. Los replicantes (Os replicantes). Anàlisi, Barcelona, n. 9, p. 71-90, 1984.

12. MATTERLART, Michele; MATTERLART, Armand. O carnaval das imagens a ficção na ficção. São Paulo: Brasiliense, 1989. p. 31.

13. BALOGH, Anna Maria. O discurso ficcional na TV. São Paulo: Edusp, 2002. p. 44. 
14. GENETTE, op. cit.

15. Apud MARTÍN-BARBERO, Jesus. De los medios a las mediaciones. Barcelona: Gustavo Gili, 1987. p. 238. [Ed. bras. Dos meios às mediações: comunicação, cultura e hegemonia. 2. ed. Rio de Janeiro: Editora UFRJ, 1997.]

16. FISKE, John. Television culture (Telecultura). London: Methuen, 1987.

17. MARTÍN-BARBERO, op. cit.

18. FEUER, Jane. Genre study and television (Estudo de gênero e televisão) In: ALLEN, Robert (Ed.). Channels of discourse (Canais de debate). London: Routledge, 1989. p. 113-133.

19. BETTETINI, Gianfranco. Conversación audiovisual: problemas de la enunciación fílmica y televisiva (Linguagem audiovisual: problemas nos discursos fílmico e televisivo). Barcelona: Cátedra, 1986.

20. BALOGH, op. cit., p. 139-153.

21. De Cassiano Gabus Mendes e direção de Jorge Fernando. Rio de Janeiro, Rede Globo de Televisão, fev./set. 1989.

22. De Antônio Calmon e direção de Marcos Paulo, Roberto Naar e Luiz Henrique Rios. Rio de Janeiro, Rede Globo de Televisão, ago./maio 2003.

23. De Antônio Calmon e direção de Jorge Fernando. Rio de Janeiro, Rede Globo de Televisão, jul. 1991/fev. 1992. fué constituído, lo que a veces es destacado de manera paratextual (novela, égloga, ensayo) y a veces silenciado" $"$.

Ora, também no tocante a essa classificação, originariamente pensada com ênfase no literário, cabem alguns adendos relativos à TV. Críticos como Paolo Fabri ${ }^{15}$ e John Fiske ${ }^{16}$, entre outros, já observaram que a TV, como veículo de comunicação de massa, está muito mais restrita a regras de gênero do que as obras consumidas pela elite, cuja apreciação se basearia não no prazer do reconhecimento presente na fruição da arte popular ${ }^{17}$, mas sim na experimentação do novo. Em suma, o reconhecimento do gênero na televisão é muito mais importante em termos de decodificação do programa televisual do que na literatura. Cabe ainda lembrar as observações de críticos como Jane Feuer $^{18}$, que constatam serem os gêneros literários muito mais consagrados, mais tradicionais e muito menos sujeitos a mudanças do que os gêneros fílmi$\cos$ e, sobretudo, os televisuais. Além disso, nos audiovisuais a categorização de gêneros nasceria de forma muito mais empírica e seria bem mais sujeita a modificações a cada nova atualização por meio dos programas seriados de TV, principalmente os de ficção.

Pode-se considerar, pois, que a paratextualidade e a arquitextualidade constituem mecanismos muito importantes de ancoragem dos sentidos na linguagem televisual, na acepção barthesiana do termo, isto é, como procedimento de estabilização do sentido do texto. A existência desses mecanismos, assim como a manutenção de formatos e grades horárias fixas (palimpsesto rígido, segundo Bettetini ${ }^{19}$ ) têm uma função reguladora que protege os espectadores da furiosa voracidade, volatilidade e obsolescência programada dos produtos seriados próprios do meio.

\section{A INTERTEXTUALIDADE CRIADORA/TRANSFORMADORA NA FICÇÃO DE TV NO BRASIL}

Em compensação, os mecanismos intertextuais utilizados na criação de programas de ficção seriada brasileira, como já se teve oportunidade de analisar detalhadamente em $O$ Discurso Ficcional na $T V^{20}$, são infinitamente mais vorazes, plurais, abarcadores e transformadores do que na maioria das obras literárias, e talvez até do que muitos dos programas do tipo na televisão estrangeira. Tais mecanismos ocorrem preferencialmente nas novelas da Rede Globo do horário das sete da noite, que têm como público-alvo os jovens. Apenas à guisa de exemplo, podem-se mencionar novelas como Que Rei Sou Eu? ${ }^{21}$, O Beijo do Vampiro $^{22}$ e Vamp $^{23}$. Nessas novelas ocorreram citações, e até plágios, dos clipes mais darks do mega-star Michael Jackson, de cineastas do gênero, além de alusões a filmes e obras literárias de vampiro, e da retomada de funções narrativas próprias, tais como abordagem das vítimas pelo ataque ou pela sedução, seguida da tradicional mordida etc. A lista poderia seguir indefinidamente, mas acredita-se que os exemplos sejam suficientemente ilustrativos para mostrar quão abarcadora e plural se tornou a ficção seriada brasileira 


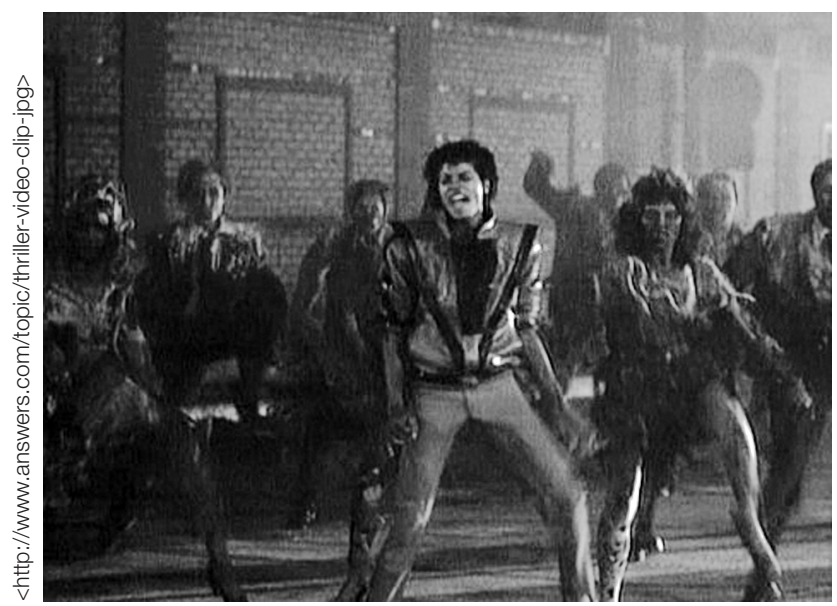

em termos de utilização criativa e transformadora da intertextualidade. Nada escapa à voracidade inovadora da TV: referências, alusões, plágios, citações; em suma, cada um dos formatos se torna, com freqüência, uma verdadeira recriação de todas as características do gênero de base utilizado na criação intertextual, recorrendo-se a todas as séries possíveis que dele tenham se servido ao longo da diacronia, e que a criação televisual usa de forma transformadora, seguindo implacavelmente a lei de Lavoisier.

Dessa forma, pode-se, a partir das considerações feitas, reformular parcialmente a definição pioneira de Kristeva, retomada no início do artigo, tendo em vista as peculiaridades da linguagem televisual. Assim teríamos que a intertextualidade designa não uma adição confusa e misteriosa de influências, mas o trabalho de assimilação de diversos textos das mais variadas séries culturais, realizado não mais por um texto de base, mas em muitos casos por um gênero inteiro com função de liderança do sentido ${ }^{24}$.

Nesse aspecto, constata-se, uma vez mais, a importância da noção de arquitextualidade para esse tipo de criação particular na produção ficcional brasileira. Nos meios audiovisuais se constata uma autêntica vampirização de diferentes textualidades em torno de um ou mais gêneros. Tal estratégia de enunciação apreensível nos enunciados dela resultantes significa com freqüência um enriquecimento na utilização criativa das mais diversas materialidades, linhas temáticas e figurativas postas em inesperados contextos ou em confronto umas com outras.

Em Television Culture, John Fiske também se manifesta sobre o caráter de bricolagem pós-moderna um tanto desvairada da TV, ao analisar o gênero televisivo:

A genre seen textually should be defined as a shifting provisional set of characteristics which is modified as each new example is produced. Any one program will bear the main characteristics of its genre but is likely to include some other ascribing it to one or another involves deciding which set of characteristics are more important ${ }^{25}$.

Tendo em mente a definição de Fiske, pode-se retornar à novela Vamp, da TV Globo, para constatar o quanto é verdadeira no tocante às estratégias de enunciação do formato, justamente em relação à criação intertextual transformadora envolvendo diferentes gêneros. Ainda que o gênero central seja o de vampiro, como bem sinaliza o próprio título escolhido, há várias incursões maiores ou menores em outros.

24. Acréscimos da autora à definição de Kristeva, apud Jenny, op. cit.

25. FISKE, op. cit., p. 111. 
26. OUT OF ÁFRICA (Entre dois amores). Direção: Sydney Pollack. Estados Unidos, 1985. 1 DVD (162 $\mathrm{min})$

27. NOSFERATU, Eine Symphonie des Grauens (Nosferatu). Direção: F. W. Murnau. Alemanha, 1922. (80 $\mathrm{min})$

28. Roman Liebling, mais conhecido como Roman Polanski, é um cineasta franco-polaco.

29. O brainstorming, ou "tempestade de idéias" é uma técnica de dinâmica de grupo, desenvolvida para explorar a potencialidade criativa do indivíduo, colocando-a a serviço de seus objetivos. (N.E.)

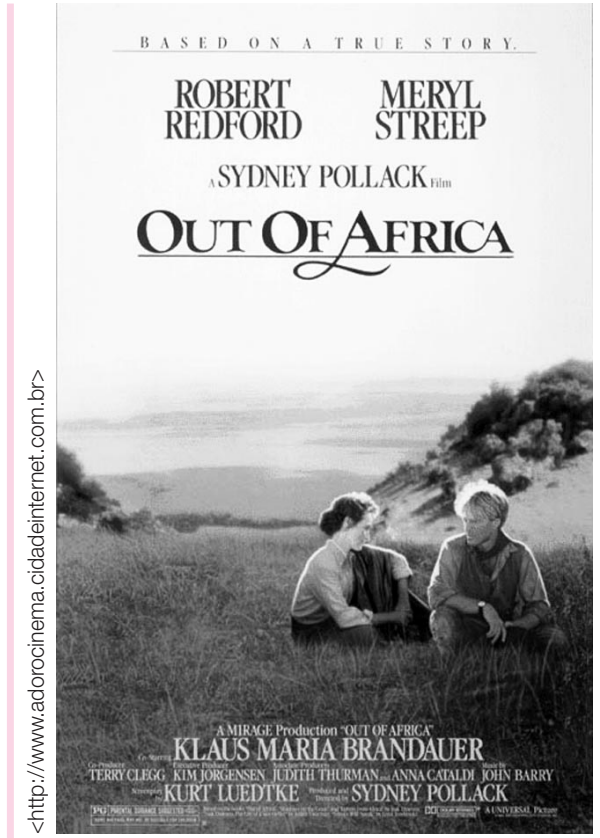

Uma incursão menor pode ser considerada sob a rubrica aventura - filmes de caçadas, na qual a caça-vampiros Miss Pentaylor (Vera Holtz) assume com tanto vigor o papel, que o seu physique du rôle inclui a indefectível roupa cáqui e o chapéu de safari, tal qual uma inglesa saída da tela de um filme como Out of Afric $a^{26}$. Uma incursão maior é feita no gênero comédia romântica de Hollywood, para retratar o casal protagonista: uma pesquisadora de histórias de vampiros (Joana Fomm) e o capitão Jonas (Reginaldo Farias), ambos viúvos com uma penca de filhos de casamentos anteriores, todos vivendo sob o mesmo teto de uma simpática pousada. O enredo remete a clássicos do gênero, como Os Seus, os Meus e os Nossos, de Nelville Shavelson, com Henry Fonda e Lucille Ball, atriz famosa pela série televisual I Love Lucy. No caso de Vamp, no entanto, todas as remissões a outros gêneros estão a serviço do gênero centralizador, que é o de vampiros, cujas situações narrativas e personagens reportam a obras emblemáticas da literatura, como a de Bram Stocker, assim como aos filmes do tipo, que podem remontar a clássicos como Nosferatu ${ }^{27}$, do expressionismo alemão, cujo lado sombrio se coaduna perfeitamente com os clipes darks de Michael Jackson citados na trama novelesca, como Thriller ou mesmo Black or White; inclusive, a troca seqüenciada de rostos que aparece neste clipe é copiada com a mais absoluta sem-cerimônia na seqüência da morte dos "vampiros do mal" liderados por um conde significativamente chamado de Polanski ${ }^{28}$ (Ney Latorraca).

Como se analisou, nada escapa à voracidade e à velocidade do meio televisivo para a criação intertextual transformadora, que pode abarcar desde simples citações ou alusões até verdadeiros brainstorming ${ }^{29}$ de diferentes gêneros, com precedência de um deles; nessa estratégia de criação se testam as possibilidades do intertextual e das diferentes materialidades que podem compor as diversas séries utilizadas até o limite. Na ficção seriada de TV, a criação parece centrada na lei de Lavoisier, desafiando a

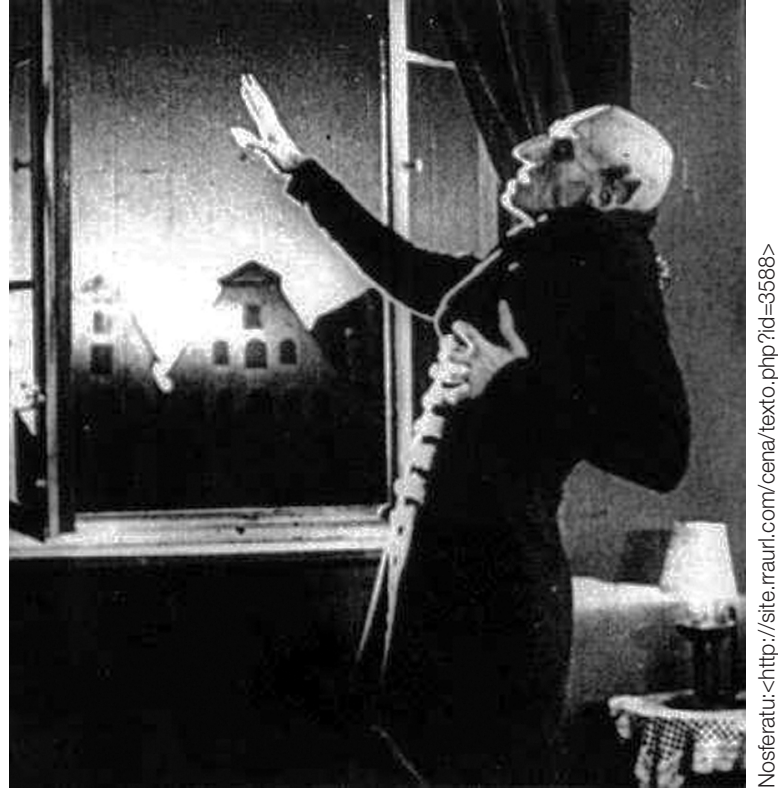




\section{Televisão • Anna Maria Balogh}

maestria de realizadores e de críticos em experimentações com os vastíssimos tecidos de relações.

Resumo: $O$ artigo discute os conceitos de intertextualidade, sobretudo a partir das propostas de Genette e revistas por Glowinski, com a finalidade de fazer as necessárias precisões e adaptações dessa metalinguagem, na origem voltada ao literário, para otimizar a análise das singularidades da televisão. Para tanto, recorre-se também aos insights de críticos da mídia, como Fiske e Vilches.

Palavras-chave: televisão, intertextualidade, paratextualidade, arquitextualidade.
Abstract: A brief review of the concepts of intertextuality based mainly on Genette's and Glowinski's views is the goal of this article. Some adaptations, changes or precisions seem necessary when theories originally aimed at literary objects are used to analyze television. The singular characteristics of television language and fiction would be, we hope, better contemplated with additional insights of critics such as Fiske and Vilches.

Keywords: television, intertextuality, paratextuality, architextuality. 